\title{
The next generation airborne polarimetric Doppler weather radar
}

\author{
J. Vivekanandan, W.-C. Lee, E. Loew, J. L. Salazar, V. Grubišić, J. Moore, and P. Tsai \\ National Center for Atmospheric Research (NCAR), Boulder, CO, USA \\ Correspondence to: J. Vivekanandan (vivek@ucar.edu) \\ Received: 27 November 2013 - Published in Geosci. Instrum. Method. Data Syst. Discuss.: 20 January 2014 \\ Revised: 16 May 2014 - Accepted: 5 June 2014 - Published: 21 July 2014
}

\begin{abstract}
Results from airborne field deployments emphasized the need to obtain concurrently high temporal and spatial resolution measurements of 3-D winds and microphysics. A phased array radar on an airborne platform using dual-polarization antenna has the potential for retrieving high-resolution, collocated 3-D winds and microphysical measurements. Recently, ground-based phased array radar (PAR) has demonstrated the high time-resolution estimation of accurate Doppler velocity and reflectivity of precipitation and clouds when compared to mechanically scanning radar. PAR uses the electronic scanning (e-scan) to rapidly collect radar measurements. Since an airborne radar has a limited amount of time to collect measurements over a specified sample volume, the e-scan will significantly enhance temporal and spatial resolution of airborne radar observations. At present, airborne weather radars use mechanical scans, and they are not designed for collecting dual-polarization measurements to remotely estimate microphysics. This paper presents a possible configuration of a novel airborne phased array radar (APAR) to be installed on an aircraft for retrieving improved dynamical and microphysical scientific products. The proposed APAR would replace the aging, Xband Electra Doppler radar (ELDORA). The ELDORA Xband radar's penetration into precipitation is limited by attenuation. Since attenuation at C-band is lower than at Xband, the design specification of a C-band airborne phased array radar (APAR) and its measurement accuracies are presented. Preliminary design specifications suggest the proposed APAR will meet or exceed ELDORA's current sensitivity, spatial resolution and Doppler measurement accuracies of ELDORA and it will also acquire dual-polarization measurements.
\end{abstract}

\section{Introduction}

NCAR's ELDORA/ASTRAIA (Electra Doppler radar/Analyese Steroscopic par Impulsions Aeroporte, hereafter referred as ELDORA) with dual-beam slotted waveguide array antennas using dual-transmitter, dualbeam, rapid scan and step-chirped waveform significantly improved the along track spatial resolution from 750 to $300 \mathrm{~m}$ when compared to NOAA's airborne tail Doppler radar (TDR) (Hildebrand et al., 1996). The ELDORA was jointly developed by NCAR and the Center de Recherché en Physique de l'Environment Terrestre et Planetaire, France. It collects research quality Doppler and reflectivity measurements that continue to set the standard for airborne radar; however, ELDORA X-band radar's penetration into precipitation is limited by attenuation and it is not designed to collect polarimetric measurements to remotely estimate microphysics. ELDORA has been placed in dormancy because its airborne platform (Naval Research Lab P-3 587) was retired in January 2013. The US research community has strongly voiced the need to continue measurement capability similar to that provided by ELDORA (Smith et al., 2012).

Signal attenuation in precipitation at $\mathrm{X}$-band is about a factor of 5 to 7 times larger when compared to C-band (Bringi and Chandrasekar, 2001). As a result, ELDORA fails to penetrate heavier precipitation regions. Figure 1 illustrates ELDORA's limitation for detecting Hurricane Rita's inner eye wall as a result of attenuation through the outer eye wall. Attenuation due to outer eye wall significantly reduced reflectivity of the inner eye wall suggesting the eye wall is weaker than it was. As the aircraft approaches closer to the eye wall the structure and intensity of the inner eye wall is revealed in the ELDORA data.

NCAR/EOL is investigating potential configurations for the next generation airborne radar that is capable of retrieving 

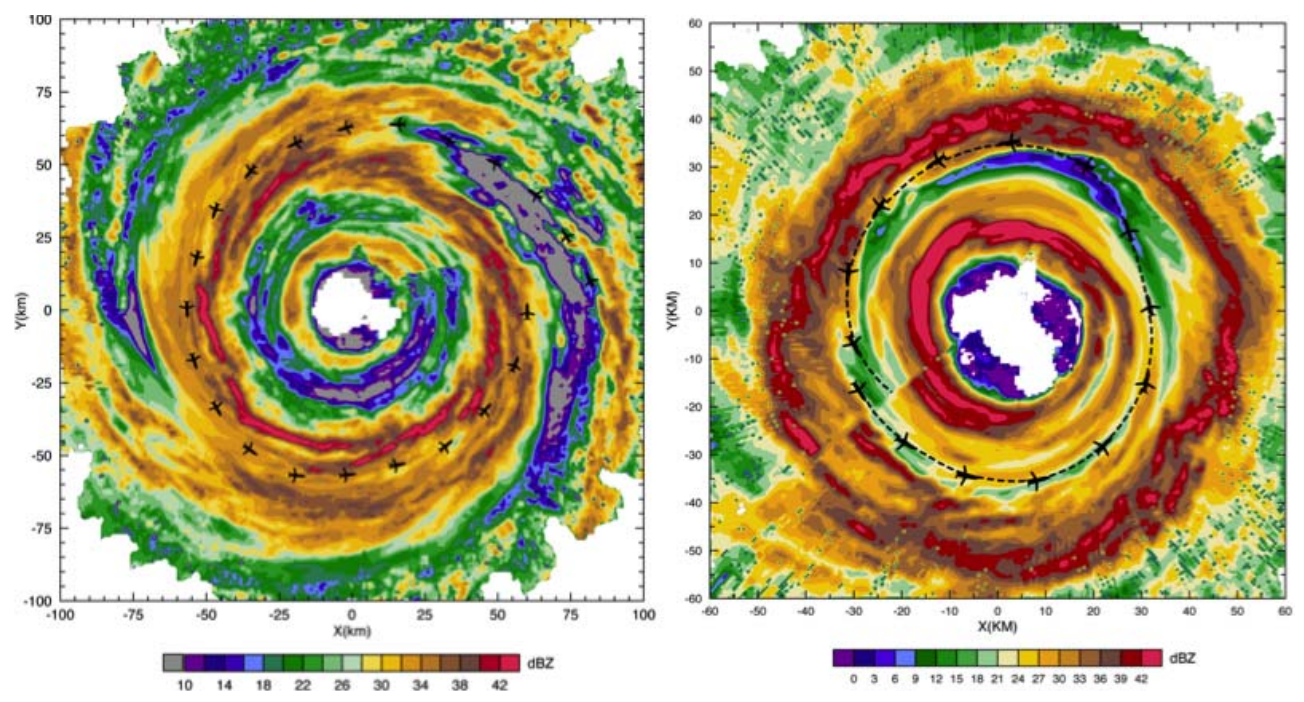

Figure 1. Hurricane Rita reflectivity from ELDORA at $2 \mathrm{~km}$ m.s.1., 22 September 2005. Attenuation at X-band limited detection of inner eye wall.

dynamic and microphysical characteristics of clouds and precipitation. Since ELDORA's slotted waveguide array radar is not compatible for dual-polarization measurements, the new design has to address both dual-polarization capability and platform requirements to replace the ELDORA system. Also, ELDORA cannot acquire the horizontal surveillance scans that are required to navigate the aircraft through regions of squall line multi-cellular storms, and/or tropical cyclones. Since the ELDORA beam is mechanically scanned using a high-speed rotodome, it is not suitable for an adaptive scan technique by which spatial and temporal resolutions can be improved.

NCAR maintains a C-130 aircraft in its fleet for airborne atmospheric measurements, including dropsonde, in situ sampling and remote sensing of clouds, chemistry and aerosols. Therefore, the addition of a precipitation radar to the NSF/NCAR C-130 platform would produce transformational change in its mission. This paper presents a possible configuration of a novel, airborne phased array radar (APAR) to be installed on the NSF/NCAR C-130 aircraft. The proposed APAR would replace the aging ELDORA. For other airborne platforms, the proposed design can be scaled up or down depending on available fuselage area for an antenna installation and desired beamwidth. Spatial resolution will be greatly improved and polarimetric measurement capability will be added to the airborne radar. Since measurements of ELDORA are recognized by the community as the best available for conducting scientific research, it is necessary for the performance of the next generation airborne radar to exceed that of ELDORA. To this end, scientific and engineering rationale for next generation airborne radar is described in Sects. 2 and 3. The proposed airborne phased array radar configuration on the C-130 is described in Sect. 4. The expected sensitivity and uncertainty in measurements are also discussed. Phased array radar system architecture and its major sub-systems are described in Sect. 5. Since airborne radar measurements are perturbed by platform motion, it is necessary to estimate true beam pointing direction and radial velocity by taking into account pitch, roll, drift, east-west velocity and north-south velocity of the aircraft. Section 6 briefly describes an automatic data quality control program for estimating true beam pointing direction and unbiased radial velocity by platform motion. Section 7 compares technical capabilities of the ELDORA and the proposed APAR. Section 8 presents a summary. Since this paper uses a number of acronyms to describe the scientific and engineering aspects of a weather radar system, an appendix lists all of the acronyms and their respective expansions.

\section{Scientific rationale for next generation airborne radar}

Airborne radar is a powerful tool to observe weather systems, in particular, storms over complex terrain, the ocean, polar regions, and forest regions not easily observable by groundbased radars (Bluestein and Wakimoto, 2003). A scanning Doppler radar on an airborne platform is used for estimating dual-Doppler winds with the help of rapid scanning as the aircraft flies past a storm. Scanning Doppler radar with dual-polarization capability on airborne platform is capable of measuring dual-Doppler winds and estimating information about particle type (ice or water) and shapes, and liquid/ice water contents using reflectivity $(Z)$, differential reflectivity $\left(Z_{\mathrm{DR}}\right)$, propagation phase $\left(K_{\mathrm{DP}}\right)$, and linear depolarization ratio (LDR). At present, no other instrument other than an airborne polarimetric Doppler phased array radar system has the potential to estimate 3-D winds and microphysics concurrently. 
The combination of remote and in situ sensors on a single airborne platform will serve the observational needs for broader scientific communities of cloud microphysics, mesoscale meteorology, atmospheric chemistry and climate, and it will fill a wide gap in the current airborne observing facilities. APAR deployed on a long-station time aircraft will allow investigation of weather systems such as monsoons, tropical cyclones, severe convection over continents, orographic precipitation, convection over the oceans, and polar and upper atmosphere chemistry. Airborne platforms, such as NSF/NCAR High-Performance Instrumented Airborne Platform for Environmental Research (HIAPER) (Laursen et al., 2006) and high-altitude long-range research aircraft (HALO) of the German Science Community (URL: http://www.dlr.de/dlr/en/desktopdefault.aspx/tabid10203/339_read-268/\#gallery/136), are better suited for aerosol and cloud measurements in UT/LS and troposphere regions. These platforms are equipped with cloud radars, lidars and in situ probes. The proposed APAR will primarily bridge the remote sensing measurement gap in high-impact weather, and it is sensitive enough for observing clouds and precipitation. The potential scientific advancements from APAR in four research areas are discussed in this section: weather, effect of clouds and aerosol on Earth's radiation budget, chemistry and transport, and calibration and validation of scientific products.

\subsection{Weather}

In recent years, hurricane genesis (Montgomery and Smith, 2012) and intensity change involving eye-eye wall interactions (Montgomery et al., 2006; Bell and Montgomery, 2008), and tropical convection related to the Madden-Julian oscillation (Zhang, 2013) have drawn research attention. These systems have their origin over the ocean and can only be sampled by radars aboard ships or aircrafts, or by spaceborne radars.

Both numerical simulations and Doppler radar observations suggest that the energy exchanges between the mostly clear and cloudy eye region and the heavy precipitation eye wall region (especially at the low levels), is a critical factor in controlling the hurricane intensity change (Houze et al., 2007). However, structures of the hurricane eye and their roles in hurricane intensity change remain largely unknown. The unique combination of APAR capabilities, which allows the measurement of 3-D kinematics in the eye and in the eye wall simultaneously as well as water vapor measurements using dropsonde and in situ measurements from a single airborne platform, will help scientists to examine the role of the hurricane eye with regard to intensity changes. The combination of measurements from dropsondes, in situ probes and Doppler radar will allow unprecedented investigations into the optimization of observing strategies and data assimilation research for improving the predictions of the track, intensity and structure of tropical and extra tropical cyclones.
A critical weather research area is quantitative precipitation estimation/forecasting (QPE/QPF). The community has determined that improved understanding of precipitation processes, from water vapor distribution and transport to QPE, requires better remote sensing, in situ observations and advanced data assimilation techniques (e.g., Emanuel et al., 1995; Dabberdt and Schlatter, 1996; Fritsch and Carbone, 2004). In the case of convective precipitation, two issues, namely, (i) when and where convection will be initiated, and (ii) determining the organization and structure of ensuing convection are key for quantitative precipitation forecast (QPF). The integration of measurements from various remote sensing and in situ instruments is a difficult problem that is amplified by having instruments on different platforms. Therefore, collocated measurements of 3-D winds and precipitation microphysics are required for achieving significant skill in QPF and quantitative precipitation estimation (QPE).

QPE using only radar reflectivity is prone to large uncertainty. Significant progress has been made in improving accuracy of QPE by combining radar reflectivity and polarimetric information. One of the factors that limits the accuracy of QPE by well-calibrated radar is a lack of detail knowledge of particle size distribution (PSD) and mean bulk density. The precipitation amount is usually estimated from radar reflectivity using a Z-LWC or IWC (liquid or ice water content) relation based on regression analysis of in situ cloud probe observation and radar reflectivity. It is known that the Z-LWC or IWC relation changes from location to location and time to time depending on changes in PSD and density (Vivekanandan et al., 1999a, 2004). Therefore, a fixed empirical Z-LWC or IWC relation cannot provide accurate QPE for various types of precipitation because it cannot represent variations in PSD and density. Polarimetric radar observations that include reflectivity, differential reflectivity and propagation phase have the potential for retrieving microphysical information of single and mixed phase precipitation. The APAR will offer the most advanced airborne dualDoppler radar with polarization capability, and will dramatically improve our ability to assess the impact of microphysical processes on QPE. Radars in dual-Doppler configuration and dual-polarization configuration for estimating dynamical and microphysical characteristics of clouds and precipitation are mostly available over land. However, storms over complex terrain, the ocean and in forest regions are not observable by ground-based radars (Bluestein and Wakimoto, 2003).

Additional in situ measurements of atmospheric tracers such as ozone will be used to broaden our understanding of atmospheric processes, such as the role of stratospheric processes in dry-air intrusions that penetrate into the tropics and cause tropical "droughts". Thus APAR would improve our ability to address key questions in water cycle research and hydrology, as well as efforts to increase understanding and prediction of high-impact weather of importance. 


\subsection{Aerosol, cloud radiation and climate}

One of the largest remaining uncertainties in assessing the future trajectory of the Earth's climate is the proper treatment of cloud processes and, in particular, the influence of aerosols on cloud formation (Houghton et al., 2001) in models. Aerosols affect cloud formation and evolution, and hence have strong indirect effects on the radiative forcing of clouds, and even on the timing and magnitude of precipitation. Models and field observations (Ramanathan et al., 2001) have shown that an increase in anthropogenic aerosols can ultimately lead to higher concentrations of cloud drops, which can enhance the cloud albedo, thereby leading to a cooling effect (Twomey, 1977) and affecting precipitation (Rosenfeld, 1999). Because these processes are highly dependent on detailed microphysics, the influence of aerosols on clouds is currently treated very crudely in the global models used to estimate future climate states.

In order to make progress in global modeling, additional measurements are necessary to constrain model parameterizations of cloud microphysics. The present state of observations is not sufficient to constrain our knowledge of the indirect effects of aerosols on clouds. Sensitivity of the APAR is expected to be better than $-14 \mathrm{dBZ}$ at ranges less than $10 \mathrm{~km}$. A threshold of $-15 \mathrm{dBZ}$ is used to distinguish regions of cloud and drizzle (Fox and Illingworth, 1997; Illingworth et al., 2007). Remote measurements alone will not be able to distinguish regions of cloud and cloud liquid, as the sensitivity of cross-polarization observation is the limiting factor. Airborne platform equipped with in situ probes and the APAR offers the opportunity to make concurrent measurements of key aerosol and microphysical constituents, respectively. These in situ and remote measurements can be compared to output from climate models (e.g., sedimentation velocities), and hence allow adjustments and improvements to model assimilation and parameterization schemes.

There is currently a debate in the community over the importance of a small particle mode for ice clouds, which is present in some in situ observations, but may also be due to instrument effects. This lack of unambiguous observations is particularly true for ice clouds in the upper troposphere, which do have a strong heating effect on the planet. These small particles affect the radiative properties of the clouds. The APAR with in situ probes is capable of estimating concentrations and spatial distributions of wind, aerosol, water vapor, cloud liquid, and cloud ice thus supporting resolution of this important question in cloud radiation research.

\subsection{Chemistry and transport}

Urban air quality, oxidant formation, acid precipitation, stratospheric ozone depletion, and climate change have profound effects on humanity and ecosystems. It is widely acknowledged that much of the recent progress in understanding atmospheric chemistry and climate has been made through intensive observational missions. While the detailed experimental design of each campaign depends on science goals, simultaneous measurements of the vertical profiles of water vapor, ozone, and aerosols are likely to be needed in most of the campaigns designed to study air quality, radiative forcing in the troposphere and UT/LS region, and the stratospheric ozone. The airborne instrumentation suite with radar and in situ probes will provide the atmospheric science community with multi-dimensional kinematics and microphysics in troposphere. This will allow for a newly comprehensive analysis of the processes controlling chemical composition of the atmosphere and interactions between chemical composition and climate. The $\mathrm{C}-130$ has a $10 \mathrm{~h}$ flight endurance, a 2900 nautical mile range, and a flight ceiling of 27000 feet. However, it should be noted C-130's ceiling altitude would limit its ability to collect any in situ observations in the UT/LS region and stratospheric ozone.

\subsection{Calibration and validation of scientific products}

It is difficult to calibrate and quantify precipitation amount and cloud property retrievals from the existing generation of space-based sensors. Tropical Rainfall Measuring Mission (TRMM) satellite is used for mapping precipitation (Simpson et al., 1998). Cloud properties are available from several recent instruments, including the CloudSat (Stephens et al., 2002), Moderate Resolution Imaging Spectoradiometer (MODIS) and GOES-R. However, there are large uncertainties in retrieving precipitation, optical properties such as sizes of cloud particles especially from the ice phase because variations in particle size distribution, crystal habit result in an ill-constrained retrieval problem. The APAR would serve as a critical validation tool for a variety of satellitebased products. Several studies have shown that polarization observables can be used to identify hydrometeor types for delineating the major precipitation types such as drizzle, rain, melting layer, snowflakes, ice crystals, and ice pellets (Vivekanandan et al., 1999a). The polarization radar technique has attracted great attention because most of the hydrometeors are non-spherical. Particularly in the case of raindrops there is a well-defined relation between size and shape (Seliga and Bringi, 1976). Polarization measurements provide additional information on precipitation and allow better microphysical characterization of hydrometeors. They are used for estimating rain rate and drop spectrum, since they depend mainly on drop size and shape (Brandes et al., 2001; Vivekanandan et al., 2004). The validation of satellite-based precipitation, aerosol, and cloud microphysical products will be critical if the data are to be used to try to understand the influence of aerosols on cloud formation, and cloud radiative properties which determine cloud radiative forcing. 


\section{Engineering rationale for next generation airborne radar}

The NWRT (The National Weather Radar Testbed) phased array radar (PAR) has demonstrated the estimation of accurate Doppler velocity and reflectivity in ground-based configuration in a single polarization mode (Forsyth et al., 2006; Weber et al., 2007; Zrnic et al., 2007). Recent NWRT measurements showed the phased array radar's ability to reduce scan time at least by a factor of 2 by rapidly steering the beam to a set of spatially diverse pointing angles using beam multiplexing (Yu et al., 2007). Beam multiplexing reduces errors in radar measurements while providing rapid updates of scan volumes. Since the airborne radar has only a limited time for collecting measurements over a specified region, beam multiplexing will significantly enhance its ability to collect high-resolution, research-quality measurements.

One of the engineering challenges is a precise estimate of polarimetric measurements using phased array radars at scan angles $>20^{\circ}$ from bore sight (Zhang et al., 2009). Reduction in polarization purity of the signals and a mismatch between orthogonal polarization beams at scan angles away from the bore sight will compromise polarimetric measurement accuracy. Limiting the polarization measurements within a $20^{\circ}$ scan angle will mostly guarantee accurate polarimetric measurements.

Participants at the workshop Meeting the Challenges of Climate System Science have enthusiastically endorsed the development of a phased array radar to replace the aging ELDORA (Smith et al., 2012). Due to the availability of large surface area of the C-130, fuselage as in the case of NSF/NCAR C-130, an antenna large enough to achieve a beamwidth comparable to ELDORA can be obtained either at C- or X-band. The next section describes a possible configuration of a phased array radar on the fuselage of the NSF/NCAR C-130 aircraft. A tail radar configuration is not supported by the C-130 due to lack of support structure in the tail. The rapid and versatile scanning capabilities of phased array radar systems lend themselves particularly well to airborne applications. Technical specifications and configuration of an airborne phased array radar capable of providing dual-Doppler wind fields and dual-polarization measurements are discussed in the following sections.

\section{APAR instrumentation and technical background}

The proposed centimeter wavelength dual-polarization Doppler radar is intended to replace the aging ELDORA and provide new research capabilities as well. A design with multiple radars on different faces of the $\mathrm{C}-130$ fuselage is shown in Fig. 2. Preliminary studies recommended flat aperture planar array antenna can be flown with a minimal impact on its flight performance.
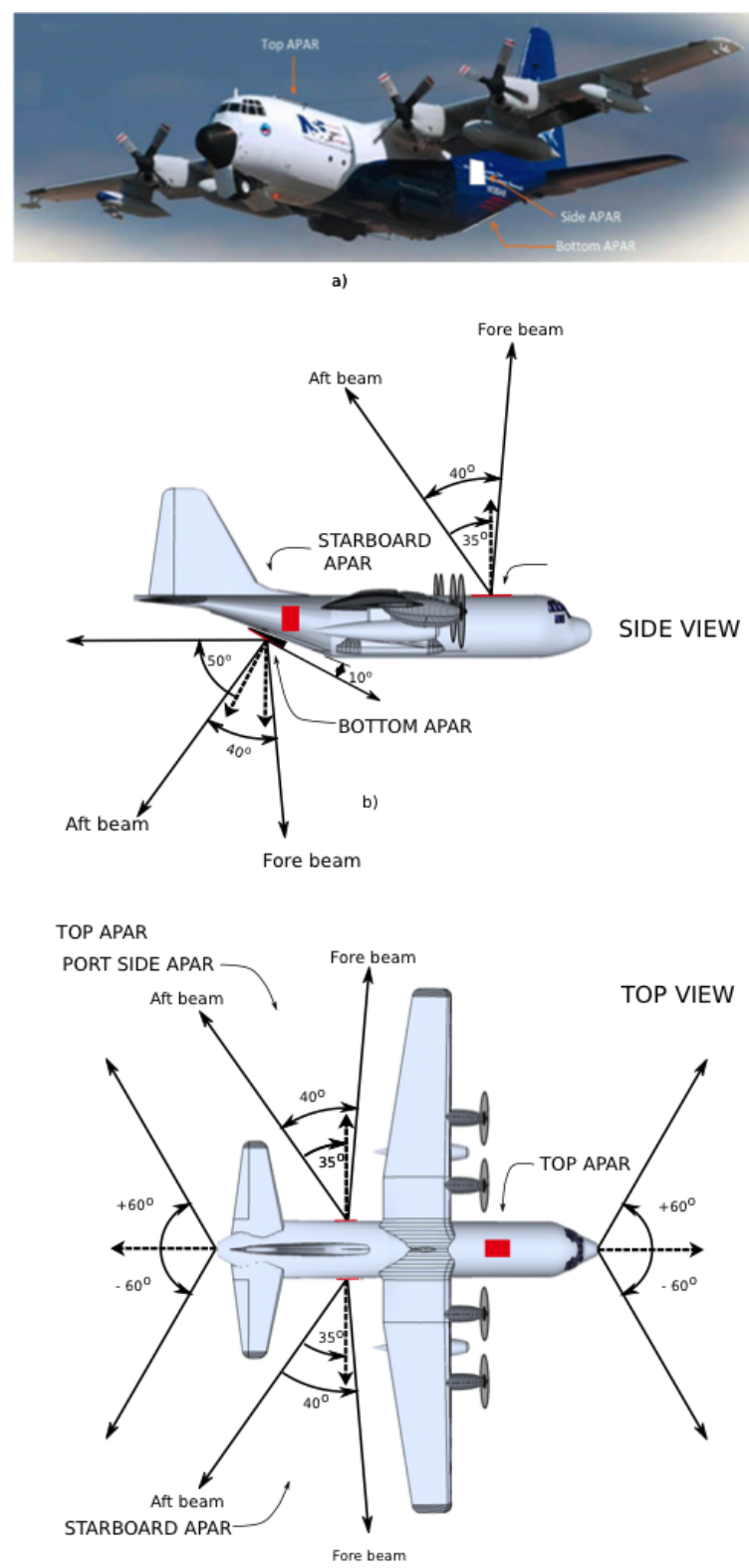

Figure 2. Proposed configuration of C-band active electronically scanned array (AESA) radars on a C-130. Four AESA radars are strategically mounted on the fuselage of the NSF/NCAR C-130 turboprop aircraft. (a) Photographs of C-130 showing locations of AESA radars, (b) side view showing top and bottom radar beams scan extent and (c) top view showing radar beams of side-looking radars.

The proposed system consists of four removable, C-band active electronically scanned array antennas (AESAs) strategically mounted on the fuselage of the NSF/NCAR C-130 turboprop aircraft using aerodynamic fairings as shown in Fig. 2. The design calls for two AESAs to be mounted on either side of the fuselage behind the rear doors; the third will be mounted on the top of the fuselage and the fourth on the 
upper portion of the tail ramp. Each AESA is approximately $1.5 \mathrm{~m} \times 1.9 \mathrm{~m}$ in size. The AESA's will be operated in two primary modes: dual-Doppler and surveillance.

Dual-Doppler (DD) mode will be the primary mode of operation. In this mode, each of the four AESAs will generate a single "pencil" beam that will be scanned in azimuth and elevation. Scanning in azimuth will be between two fixed angles, one fore and one aft. The fore and aft azimuth angles will be separated by $35^{\circ}$ as shown in Fig. 2. It is likely that given the proposed configuration on the $\mathrm{C}-130$ the fore and aft azimuth angles will not be symmetrical about $0^{\circ}$ (normal to the flight track) as is the case for the present ELDORA system. Fore and Aft azimuth values are more likely to be $+5^{\circ} /-30^{\circ}$ normal to the flight track. As shown in Fig. 2, the location of the side-looking radars with regard to wings and tail causes asymmetry in aft and fore azimuth angles of the beams. Scanning will be done to maximize the number of independent samples, while covering the desired spatial domain $\left( \pm 50^{\circ}\right.$ in elevation) in the least amount of time. This strategy will produce optimal resolution dual-Doppler data. In order to implement this scan strategy, switching in both azimuth and elevation scan angles must be accomplished in less than $5 \mu$ s. Doppler velocity will be computed on pairs of pulses separated by the pulse repetition time (PRT) at a given azimuth and elevation. The beam will then be steered to another position and another pair of pulses will be transmitted. This process will continue until the time to independence, or decorrelation time, has been reached for the original starting position and the sequence will repeat again. Once enough independent pairs have been collected, the velocity estimates from the pairs of pulses at each elevation and azimuth can be averaged for reducing standard error in radial wind and reflectivity estimates. Based on the decorrelation time, the entire spatial quadrant that each radar is required to cover can be divided into a finite number of such sequences. Dual-polarization measurements will be collected by transmitting alternatively in horizontal and vertical polarizations in the fore direction in dual-polarization and dual-Doppler (DPDD) scan mode. Polarimetric measurements will be collected only over restricted elevation angles. The collection of dual-polarization measurements will require about $20 \%$ more scan time than Doppler-only measurements. This assumes that these measurements will be made with the forward looking beam only and over $\mathrm{a} \pm 20^{\circ}$ sector in elevation.

A secondary surveillance scan mode will be interleaved periodically with the primary mode to produce a "composite" PPI scan which incorporates data from the three aft mounted AESAs and the weather avoidance radar located in the nose of the aircraft. In surveillance mode, the elevation angle is held fixed at $0^{\circ}$ and the beam is scanned in azimuth. It is envisioned that other scan strategies will be incorporated over time, but scan limits will remain unchanged. Figure 3 shows the locations of the four AESA radars with respective beam scanning modes (dual-Doppler and reflectivity) and the weather avoidance nose radar on the C-130 as well as a com-

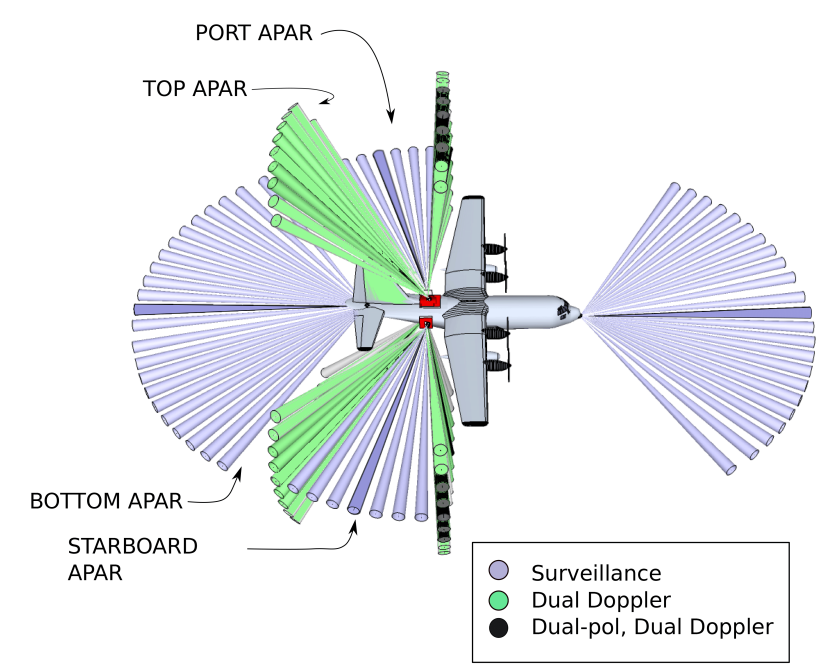

Figure 3. Typical beam positions of the proposed four AESA radars and weather avoidance radar on the C-130. Doppler, dualpolarization and surveillance beam positions are shown in various colors.

posite surveillance scan. Various scan timing sequences for dual-Doppler, dual-polarization, and surveillance are shown in Fig. 4.

The "composite" scanning of all four AESAs yields a full $360^{\circ}$ dual-Doppler coverage, as in the current ELDORA. An important advantage of the AESAs over ELDORA is the ability to scan in azimuth as well. This feature, used in conjunction with data from the C-130 weather avoidance radar, will be exploited to produce a composite PPI "surveillance" scan as depicted in Fig. 3. This "surveillance" mode is essential to provide safety in single aircraft missions and will also aid in mission flight planning while in the air.

\subsection{Selection of wavelength}

S-band, due to the limited antenna aperture area on C-130 fuselage, will have significantly diminished spatial resolution of radar measurements; therefore, X-band and C-band were considered for use in APAR. Using the available aperture at C-band will produce a radar beamwidth of $\sim 2^{\circ}$. Using the same size aperture at $\mathrm{X}$-band will produce a radar beamwidth of $\sim 1^{\circ}$; while this option may be attractive for improved spatial resolution, it would require four times the number of radiating elements and consequently would be prohibitively expensive to build.

Sensitivity at X-band is about $5 \mathrm{~dB}$ better than C-band in the absence of any significant attenuation due to precipitation, given comparable antenna gain and transmit power. However, attenuation due to precipitation at C-band is five to seven times or $8 \mathrm{~dB}$ smaller when compared to X-band, and $\mathrm{X}$-band cumulative attenuation through precipitation is significant. C-band radar transmit signals will penetrate deeper into squall lines and rainbands. Due to these considerations, 


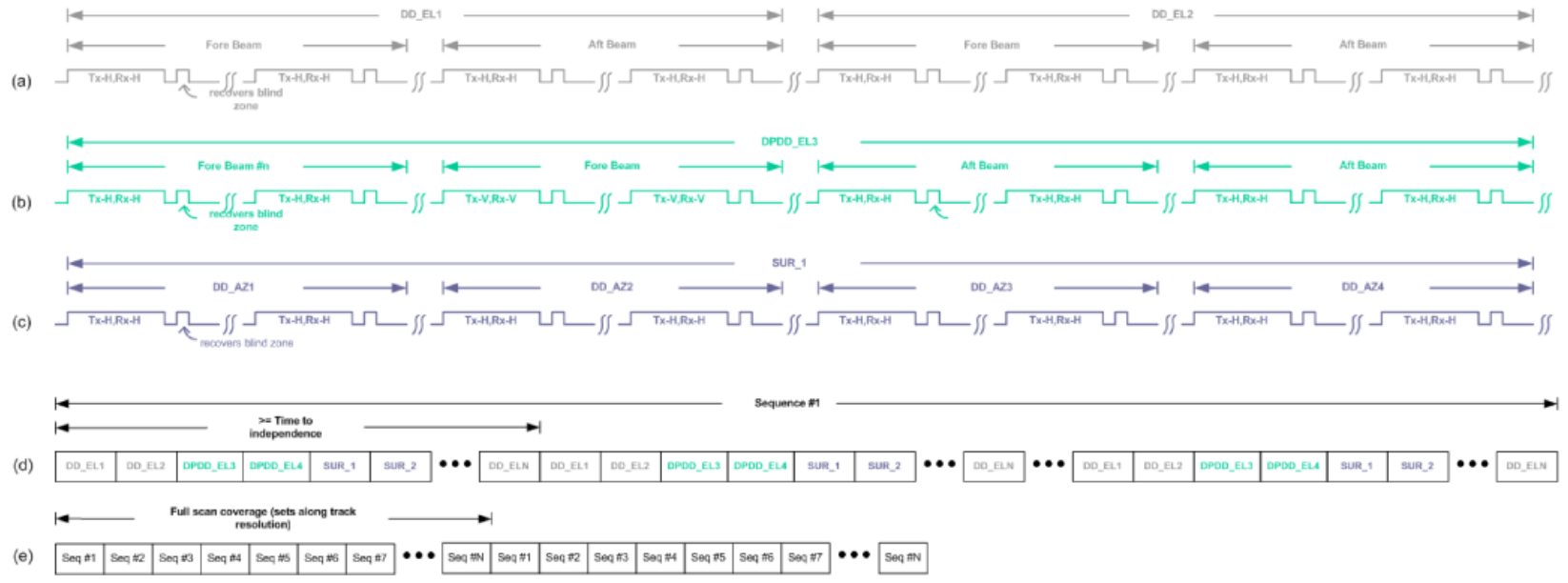

Figure 4. APAR scan timing sequences: (a) dual-Doppler (DD) timing for two successive elevation angles, (b) dual-polarization and dualDoppler (DPDD) timing for a single elevation angle, (c) surveillance scan timing for four successive azimuth angles, (d) a typical scan sequence comprising dual-Doppler, dual-polarization, and surveillance scans using beam multiplexing, and (e) full scan coverage in elevation and azimuth that determine along track resolution. During DD and DPDD scans, measurements are collected at various elevation angles, for both fore and aft beam positions. Surveillance scan is performed for a fixed elevation angle by scanning in azimuth.

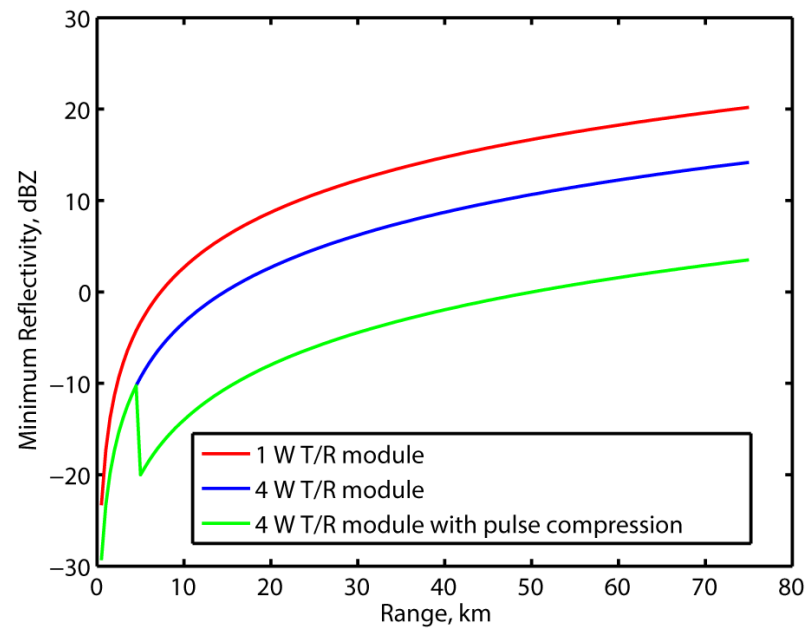

Figure 5. Sensitivities of the APAR for $1 \mathrm{~W}$ and $4 \mathrm{~W}$ transmit/receive (T/R) modules and $4 \mathrm{~W}$ T/R modules with $33: 1$ pulse compression are shown as a function of range. PAR is designed to transmit short pulse of $1 \mu$ s for sampling the blind zone created by $33 \mu$ s long pulse as depicted in green curve. Transmission of short and long pulses leads to abrupt change in sensitivity at $5 \mathrm{~km}$.

C-band was selected. Attenuated X- and C-band radar measurements can be corrected using $K_{\mathrm{DP}}$ and $Z_{\mathrm{DR}}$ observations (Chang et al., 2014). However when the measured signal is below the system noise floor due to significant attenuation in rainbands, melting region, and squall line corrections to the attenuated signal is not feasible.

\subsection{Sensitivity}

The proposed airborne phased array radar (APAR) will estimate dynamical and microphysical properties of clouds and precipitation in conjunction with in situ sampling of the same. Various technical specifications of AESA radar were investigated. Technical characteristics of one such configuration that has better sensitivity for measuring reflectivity and more accurate radial mean velocity than ELDORA are listed in Table 1.

Each APAR is composed of 3584 active, radiating elements, arranged in a rectangular array of $7 \times 8$ line replaceable units (LRU). Each LRU is composed of 64 radiating elements. Each radiating element will use a stacked patched microstrip antenna radiator coupled to a transmit/receive (T/R) module. The microstrip patch antenna elements can transmit in either horizontal $(\mathrm{H})$ or vertical $(\mathrm{V})$ polarizations. The radiating elements are spaced less than half a wavelength apart to avoid grating lobes over the full scan extent (Wang et al., 2008). In the transmit mode all of the $T / R$ modules transmit at the peak power for the best power aperture efficiency. The resulting uniform illumination will produce a sidelobe that is $13 \mathrm{~dB}$ lower than the main lobe in the transmit mode. In the receive mode, the antenna sidelobe level is reduced by tapering receive aperture antenna illumination by a 2-D Taylor distribution weighting function.

Commercial T/R modules at C-band have been identified which can transmit either $1 \mathrm{~W}$ or $4 \mathrm{~W}$ peak power. Solid state $T / R$ modules are capable of transmitting long pulses for significantly improving average transmit power. They can transmit variable pulse lengths between 0.5 and $50 \mu \mathrm{s}$. In the case of $1 \mathrm{~W} T / \mathrm{R}$ module with $1 \mu$ s pulse width, the total peak transmit power is $3.6 \mathrm{~kW}$. Radar sensitivity is linearly 
Table 1. Technical specifications of C-band APAR and ELDORA.

\begin{tabular}{|c|c|c|}
\hline Parameter & APAR & ELDORA \\
\hline Frequency & $5.4 \mathrm{GHz}$ & $9.3-9.8 \mathrm{GHz}$ \\
\hline Wavelength & $5.55 \mathrm{~cm}$ & $3.2 \mathrm{~cm}$ \\
\hline $\begin{array}{l}\text { Element spacing along par- } \\
\text { allel and perpendicular to } \\
\text { fuselage }\end{array}$ & $2.78 \mathrm{~cm}, 2.78 \mathrm{~cm}$ & $\mathrm{n} / \mathrm{a}$ \\
\hline $\begin{array}{l}\text { Number of elements along } \\
\text { parallel and perpendicular } \\
\text { to fuselage }\end{array}$ & $\begin{array}{l}56,64 \\
(3584 \text { elements })\end{array}$ & $\mathrm{n} / \mathrm{a}$ \\
\hline $\begin{array}{l}\text { Line replacement unit } \\
\text { size (LRU) }\end{array}$ & $8 \times 8(64$ elements $)$ & $\mathrm{n} / \mathrm{a}$ \\
\hline Number of LRUs per PAR & $7 \times 8(56$ LRUs $)$ & $\mathrm{n} / \mathrm{a}$ \\
\hline antenna beamwidth: & $\theta_{0}: 1.8^{\circ}, 1.6^{\circ}$ & $2.0^{\circ}, 1.8^{\circ}$ \\
\hline $\begin{array}{l}\text { (elev, azim) in transmit } \\
\text { mode (uniform aperture } \\
\text { illumination) }\end{array}$ & $\theta_{45}: 2.1^{\circ}, 1.8^{\circ}$ & $\mathrm{n} / \mathrm{a}$ \\
\hline $\begin{array}{l}\text { Antenna beamwidth :(elev, } \\
\text { azim) in reception mode } \\
\text { (Taylor aperture } \\
\text { illumination) }\end{array}$ & $\begin{array}{l}\theta_{0}: 1.9^{\circ}, 2.2^{\circ} \\
\theta_{45}: 2.2^{\circ}, 2.5^{\circ}\end{array}$ & $\begin{array}{l}2.0^{\circ}, 1.8^{\circ} \\
\mathrm{n} / \mathrm{a}\end{array}$ \\
\hline Antenna gain: & $40 \mathrm{~dB}$ (uniform) & $39 \mathrm{~dB}$ \\
\hline Transmit & $39 \mathrm{~dB}$ & $39 \mathrm{~dB}$ \\
\hline Receive & (Taylor taper) & \\
\hline Polarization & $\mathrm{H}, \mathrm{V}$ Linear & $\mathrm{H}$ only \\
\hline Peak transmit power & $\sim 14$ kW (4W/TR) & $35-40 \mathrm{~kW}$ \\
\hline Range resolution & $150 \mathrm{~m}$ & $150 \mathrm{~m}$ \\
\hline $\begin{array}{l}\text { Minimum along track } \\
\text { sweep spacing }\end{array}$ & $130 \mathrm{~m}$ & $300 \mathrm{~m}$ \\
\hline Radar angular resolution & $\sim 0.3 \mathrm{~km} @ 10 \mathrm{~km}$ & $\begin{array}{l}\sim 0.3 \mathrm{~km} @ \\
10 \mathrm{~km}\end{array}$ \\
\hline $\begin{array}{l}\text { Minimum detectable } \\
\text { signal (at } 10 \mathrm{~km})\end{array}$ & $-14 \mathrm{dBZ}$ & $-11 \mathrm{dBZ}$ \\
\hline
\end{tabular}

proportional to the peak transmit power. As shown in Fig. 5, sensitivity of a $4 \mathrm{~W}$ T/R element is better than a $1 \mathrm{~W} T / \mathrm{R}$ element by $6 \mathrm{~dB}$; however, the $4 \mathrm{~W} \mathrm{~T} / \mathrm{R}$ module does not meet the requirement of $-12 \mathrm{dBZ}$ sensitivity at $10 \mathrm{~km}$. By transmitting $33 \mu$ s pulse, $4 \mathrm{~W}$ T/R module and using a pulse compression scheme, the sensitivity is improved to $-20 \mathrm{dBZ}$ at $10 \mathrm{~km}$. A $33 \mu \mathrm{s}$, non-linear frequency modulated (NLFM) pulse will be compressed to a final range resolution of $150 \mathrm{~m}$. The long pulse of $33 \mu$ s creates a blind zone of $5 \mathrm{~km}$ around the aircraft. The blind zone can be eliminated by transmitting an intermittent short pulse of $1 \mu$ s. PAR is designed to transmit long pulse and short pulse concurrently (Salazar et al., 2010). For simultaneous reception of long and short pulses, a dual-channel down converter is included. Transmission of short and long pulses leads to an abrupt change in sensitivity at a $5 \mathrm{~km}$ range. Since at a range less than $5 \mathrm{~km}$ the radar will detect better than $-10 \mathrm{dBZ}$, the abrupt change in sensitivity due to long and short pulses will have no impact on detecting precipitation echo at close ranges.

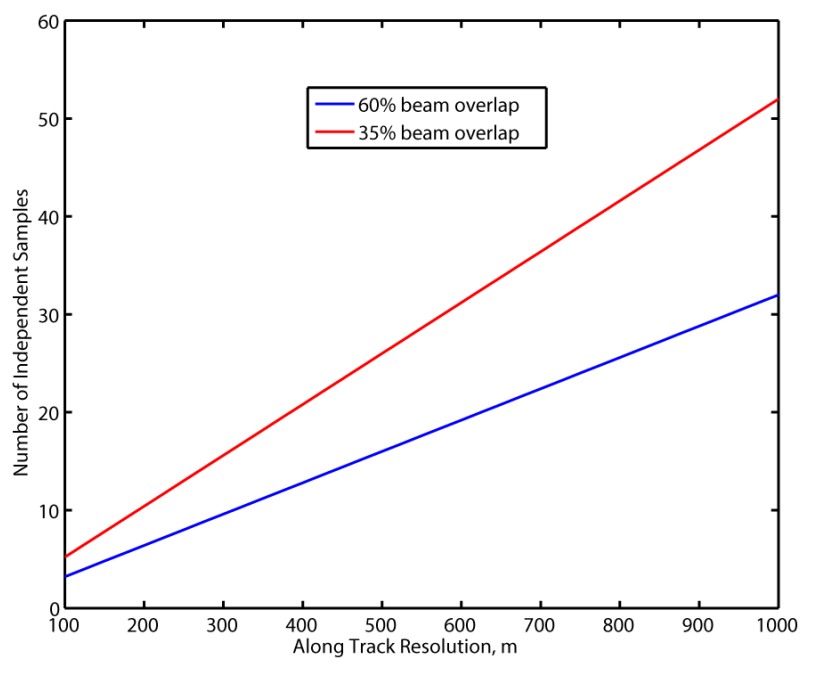

Figure 6. Number of independent samples verses along track resolution are shown for 35 and $60 \%$ beam overlaps. The PRF is assumed 2000. Aircraft speed is assumed to be $125 \mathrm{~m} \mathrm{~s}^{-1}$.

\subsection{Along track resolution and sampling of radar signals}

One of the key benefits of an electronically scanned (e-scan) radar is beam multiplexing. Since the beams can be instantaneously steered from one position to the next in an e-scan mode, scan sequences can be programmed for collecting only independent samples over the desired scan volume. Typically, only two pulses are transmitted for acquiring a pulsepair estimate and then the beam is pointed at a different scan angle to collect the next sequence of independent samples. The beam is returned to the previous scan position only after the time to decorrelation is elapsed. At C-band, time to decorrelation $\left(T_{\mathrm{D}}\right)$ is $6.2 \mathrm{~ms}$ for a Doppler spectrum width of $1 \mathrm{~m} \mathrm{~s}^{-1}$. The beam multiplexing technique allows for a reduction in the dwell time needed to acquire a sufficient number of independent samples. Averaging the signals of independent samples reduces fluctuation in radar estimates of wind and reflectivity. Figure 6 shows independent samples verses along track resolution for a specified aircraft speed and PRF. The larger the overlap between beams, better the angular resolution, but it will lead to fewer independent samples as it requires more time for scanning for a specified angular sector. Limiting the beam overlap to $35 \%$, for an along track resolution of $400 \mathrm{~m}, 20$ independent samples can be obtained. It should be noted, the number of independent samples in the mechanically scanned antenna is determined by the dwell time of the beam, which is primarily determined by aircraft speed for a specified scan rate. 


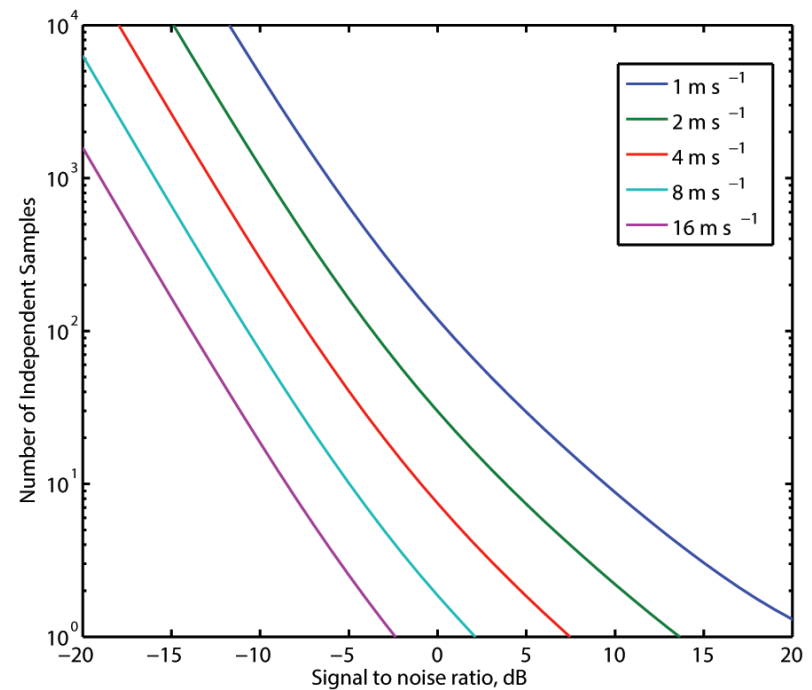

Figure 7. Requirement of number of independent samples as a function of signal-to-noise ratio for various mean velocity measurement accuracies are shown. Spectrum width is assumed $1 \mathrm{~m} \mathrm{~s}^{-1}$ and PRF is 2000 and transmit frequency is C-band.

\subsection{Measurement accuracy of mean velocity}

The measurement accuracy of Doppler radial velocity is a function of time-to-independence $\left(T_{\mathrm{D}}\right), \mathrm{PRF}$, and signalto-noise ratio (SNR) (Doviak and Zrnic, 1993). Time-toindependence determines the interval between two radar measurements that are statistically independent. It is a function of transmit frequency and spectrum width (Bringi and Chandrasekar, 2001). In the case of C-band, $T_{\mathrm{D}}$ is larger than in the corresponding value at $\mathrm{X}$-band. However, beam multiplexing offers the option for collecting more independent samples in the case of PAR.

Figure 7 shows the number of independent samples required as a function of signal-to-noise ratio (SNR) for various measurements of mean radial velocity accuracies. For 20 independent samples, SNR of $6 \mathrm{~dB}$ is required for estimating radial velocity within $1 \mathrm{~m} \mathrm{~s}^{-1}$ accuracy. Despite larger $T_{\mathrm{D}}$ at C-band, the e-scan feature of PAR allowed to estimate radial velocity within $1 \mathrm{~m} \mathrm{~s}^{-1}$ accuracy without much increase of SNR compared to ELDORA. Comparison of independent samples as a function of SNR between the APAR and ELDORA are shown in Sect. 7.

\subsection{Polarization option for phased array radar}

Conventional weather radars make polarimetric measurements in three distinct transmit/receive modes: (i) alternate transmit and alternate receive (ATAR), (ii) alternate transmit and simultaneously receive (ATSR), and (iii) simultaneously transmit and simultaneously receive (STSR). For STSR, any cross-coupling between horizontally $(\mathrm{H})$ and vertically $(\mathrm{V})$ transmitted/receive waves in the hardware and/or propaga-
ATAR T\R MODULE ARCHITECTURE

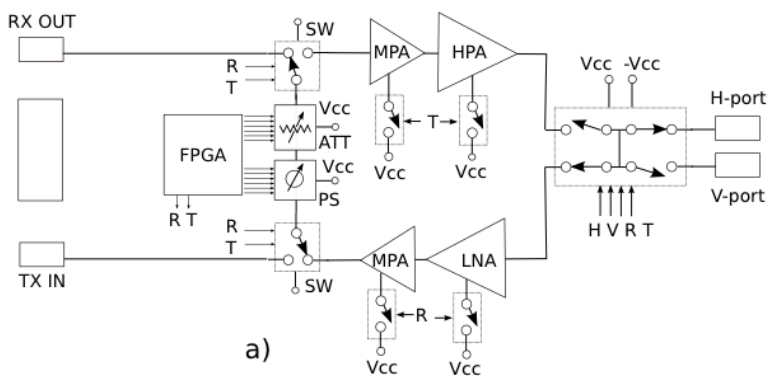

ATSR T\R MODULE ARCHITECTURE

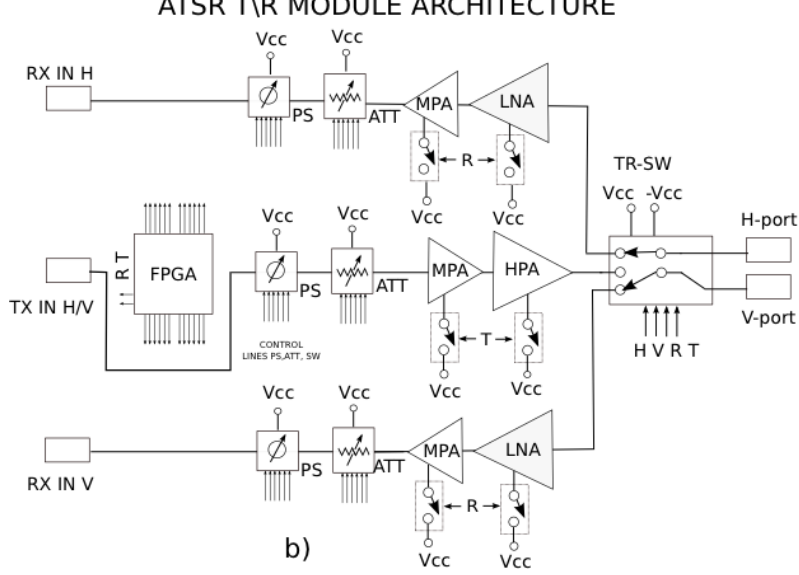

Figure 8. TR-Module architecture options for APAR: (a) dualpolarization for alternate transmit and alternate receive (ATAR) (b) dual-polarization alternate transmit and simultaneous receive (ATSR) modes The acronyms in the figures are listed in the appendix with their respective expansions.

tion medium due to canted hydrometeors would bias differential reflectivity $\left(Z_{\mathrm{DR}}\right)$ measurement (Hubbert et al., 2010a, b). For example, in STSR mode, better than $44 \mathrm{~dB}$ isolation between $\mathrm{H}$ and $\mathrm{V}$ channels is required to insure that bias in $Z_{\mathrm{DR}}$ is less than $0.2 \mathrm{~dB}$ (Wang and Chandrasekar, 2006); this requirement is extremely difficult to meet using stacked-patch microstrip antenna technology. Also, in the STSR mode, cross-polarization measurement is not feasible as the radar transmits in both horizontal and vertical polarizations simultaneously. In ATAR and ATSR modes $20 \mathrm{~dB}$ isolation between $\mathrm{H}$ and $\mathrm{V}$ channels is sufficient for limiting bias in $Z_{\mathrm{DR}}<0.2 \mathrm{~dB}$ (Wang and Chandrasekar, 2006; Bringi and Chandrasekar, 2001). For estimating microphysics, rain rate, and ice and liquid water contents, differential reflectivity $\left(Z_{\mathrm{DR}}\right)$, specific propagation phase $\left(K_{\mathrm{DP}}\right)$, and co-polar correlation coefficient $\left(\rho_{\mathrm{hv}}\right)$ are preferred (Vivekanandan et al., 1999a, b). From engineering considerations, alternate transmit mode is preferred for acquiring the above-mentioned polarization measurements.

The APAR system can be designed to operate in one of two modes: (i) ATSR which requires two receive channels and, (ii) ATAR (alternate transmit and alternate receive) which 
requires one receive channel. Figure 8 shows transmit and receive architectures for ATSR and ATAR modes. In the alternating transmit mode, both co- and cross-polarization measurements, such as full scattering matrix, are possible. A number of simulation studies and measurements of beam patterns suggest high-quality polarimetric measurements could be collected over limited scan coverage from boresight (Zhang et al., 2009).

In ATAR configuration, co- and cross-polarization returns are measured by alternating transmit pulses between horizontal and vertical polarizations. While LDR can still be measured, twice as many pulses will be required to achieve the same objective, thereby reducing spatial resolution by a factor of 2 over ATSR for cross-polarization measurements; copolarization measurements are made at the same spatial resolution. Since the strategy for APAR is to acquire polarimetric measurements over a restricted range of scan angles $\left(5^{\circ}\right.$ in Azimuth and $\pm 20^{\circ}$ in elevation), the reduction in spatial resolution of making cross-polarization measurements using an ATAR architecture is not significant. However, the cost of implementing the ATAR architecture over the ATSR architecture is significantly reduced due to the lower component count in each of the T/R elements.

For precise measurements of the above-mentioned polarimetric measurements, horizontal and vertical antenna patterns of the main beam must be in excellent agreement spatially. This not only applies to broadside, but also as the beam is scanned in azimuth and elevation. A secondary polarimetric capability is to acquire quality cross-polar measurements, namely, linear depolarization ratio (LDR). To achieve this objective, integrated cross-polar ratio (ICPR) is the defining property. For estimating intrinsic LDR of $-27 \mathrm{~dB}$ within $1 \mathrm{~dB}$ error, ICPR must be better than $-30 \mathrm{~dB}$ (Bringi and Chandrasekar, 2001). Since the expected ICPR of microstrip patch antenna will be at the most $-25 \mathrm{~dB}$, the lowest LDR value detected by the APAR will be $-22 \mathrm{~dB}$. This applies not only to broadside, but also as the beam is scanned in azimuth and elevation. In order to limit the effect of differential gain due to beam pattern variation on polarimetric measurements, polarization measurements will be collected only up to $\pm 20^{\circ}$ from bore sight. The minimum LDR of $-22 \mathrm{~dB}$ will delineate regions of liquid, ice, and mixed phase but discrimination between various types of ice crystals and detection of cloud ice will be compromised.

\section{Description of the phased array radar architecture}

It is common for a phased array radar antennas to be modular in design. As alluded to earlier, each APAR is composed of 3584 active, radiating elements arranged in a rectangular array of $7 \times 8$ line replaceable units (LRU). Each LRU is an identical sub-array composed of $8 \times 8$ radiating elements. Each sub-array consists of a number of solid-state transmit/receive (T/R) elements coupled to microstrip patch

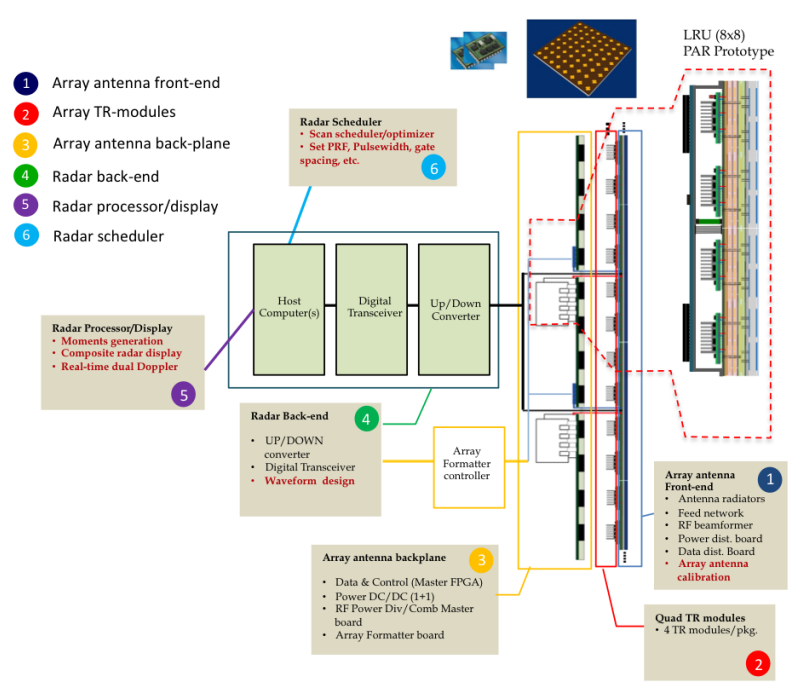

Figure 9. Simplified block diagram of PAR. It consists of six components: (1) the RF array antenna front end, (2) quad T/R modules, (3) array antenna backplane and (4) radar digital back end (5) radar processor/display and (6) radar scheduler.

antennas. Each radiating element can transmit and receive in horizontal or vertical polarization modes. The stacked patch microstrip antenna array is designed to have better than $-25 \mathrm{~dB}$ cross-polarization isolation in the diagonal plane and a mismatch below $5 \%$ between co-polar pattern for a scanning range between $\pm 45^{\circ}$. The above specified antenna characteristics would guarantee measurements of $Z_{\mathrm{DR}}$ within $0.2 \mathrm{~dB}$ accuracy in the ATAR and ATSR mode of operations.

Figure 9 shows a simplified block diagram of the proposed APAR. It consists of six modules: (1) the radio frequency (RF) array antenna front end, (2) quad T/R modules, (3) array antenna backplane, (4) radar digital back end, (5) radar processor/display, and (6) radar scheduler. The RF array antenna front end includes low-profile dual-polarization microstrip antenna radiators, a power distribution board and a data distribution board. Antenna elements are placed in a square lattice separated by $\sim 0.5 \lambda_{0}$, where $\lambda_{\mathrm{o}}$ is the transmit wavelength, to avoid grating lobes at all scan angles. Radiating elements will be designed to have a robust performance over 10 to $15 \%$ the bandwidth of C-band. The quad T/R module consists of a matrix of $2 \times 2$ individual T/R modules. It is a multi-layer printed circuit board that included monolithic microwave integrated circuits (MMIC) components, namely, digital phase shifters, attenuators, power amplifier (PA), low noise amplifier (LNA), high-speed pin diode switches, and a field programmable gate array (FPGA). The digital 6 bit phase shifter supplies the necessary phase to the RF signal for steering the beam in a specified direction. The digital attenuator tapers transmit and receive amplitudes across the active aperture for reducing antenna sidelobes and also for aligning the amplitudes of each T/R element. Receive amplitudes are tapered across the aperture to lower sidelobes. 
In the transmit mode, no tapering is applied to maximize the peak transmit power. The phase shifter and attenuator are reciprocal devices and they are placed in common transmit and receive signal paths.

The high power amplifier (HPA) amplifies RF transmit signal and is capable of handling pulse duration between 0.25 and $50 \mu \mathrm{s}$. It dissipates a significant amount of power and the heat generated must be removed for safe operation of the $\mathrm{T} / \mathrm{R}$ module. The HPA has the shortest lifetime among all of the components in the T/R module due to its self-heating. Heatsinks are placed outward into the space between the antenna aperture and backplane printed circuit boards. Cooling can be accomplished via forced convection or a cold plate. A low noise amplifier (LNA) determines the noise figure of the receive chain and it is placed closest to the receive port of the antenna. Each T/R element is coupled to a two-port radiator for dual-polarization transmission and reception. The FPGA controls the attenuator, phase shifter, and switches for the desired performance of APAR.

The array antenna backplane includes master FPGAs for communicating scan angle, polarization, and pulse information to the FPGAs in each LRU from the radar scheduler. The radar back end consists of up and down converters between intermediate frequency (IF) and RF, digital transceivers, and a host computer for generating radar measurements, namely, mean velocity, spectrum width, and dual-polarization observables and displaying the same.

\section{Airborne Doppler radar data quality control}

The dual-beam radar mode requires additional postprocessing of the data. In the case of airborne radar true beam pointing direction and radial velocity are perturbed by platform motion. Raw airborne Doppler data contain both weather and non-weather echoes that require editing and quality control (QC) prior to wind synthesis, but interactive QC has been a hindrance for researchers due to the time and training required to properly identify non-weather radar echoes. The interactive QC process of airborne Doppler radar data using the NCAR Solo software (Oye et al., 1995) requires a significant amount of time even for experienced radar meteorologists, with rough estimates of at least $30 \mathrm{~min}$ to edit a single radar scan. As a result, interactively editing of $10 \mathrm{~min}$ worth of ELDORA (or $50 \mathrm{~min}$ worth of NOAA P3) radar data takes approximately $240 \mathrm{~h}$ ( $\sim 6$ weeks $)$ by this estimate. EOL has developed automatic data quality control of ELDORA data and real-time estimation of dual-Doppler winds (Bell et al., 2013). This package will be adapted for the APAR e-scan system.

An automated Solo-based airborne Doppler radar data QC algorithm has been developed to handle a wide range of meteorological conditions that can significantly reduce editing time (Bell et al., 2013). This set of batch Solo-based editing scripts can be tuned to remove different degrees of non- weather returns depending on the specific scientific needs. For example, the threshold can be lower (higher) for detail process studies (data assimilation). The script can be distributed to existing Solo users without requiring additional software. The batch script can reduce the editing time tenfold (i.e., from months to days) making the post analysis of airborne Doppler radar much more efficient for even novice users. The algorithm could be run in near-real time during a research flight to aid a mission scientist in making decisions about where to next send the aircraft (Houze et al., 2006), or be used to prepare airborne radar data for assimilation into numerical weather prediction models (Zhang et al., 2012). The automatically pre-processed data can also serve as a useful starting point for further interactive editing for detailed case studies in post analysis mode (Schmitz, 2010).

\section{Comparison of technical capabilities of the ELDORA and APAR}

It is imperative that the proposed APAR's capability should exceed ELDORA's capability. ELDORA is the most sensitive scanning airborne centimeter wavelength radar and it collects measurements at the best spatial and temporal resolutions (Bluestein and Wakimoto, 2003). A back-to-back slotted waveguide array antenna configuration allows the transmission of two simultaneous beams that are at a $36^{\circ}$ angle relative to one another for dual-Doppler measurements as shown in Fig. 10 for dual-Doppler measurements. ELDORA is configured as rotating tail radar aboard a P-3 aircraft. The dual-beam configuration allows for estimation of 2-D winds fields from a single straight-leg flight when compared to quasi-perpendicular flight legs in the case of a single beam NOAA P-3 radar (Jorgensen et al., 2000). Non-requirement of perpendicular flight legs simplified ELDORA flight patterns for observations of squall lines and intervening convective cells, as well as rainbands that do not develop along a straight line. ELDORA is the only airborne Doppler radar which resolves convective scale with certainty.

A typical flight track of ELDORA for observing a convective cell is shown in Fig. 10. Two separate radar beams are pointing aft and fore of the aircraft to simultaneously collect measurements for estimating dual-Doppler winds. As the aircraft flies in a straight path, the rotation of the flat panel antennas about the aircraft's longitudinal axis sweeps two conical helixes. In any given plane, fore and aft beams are separated by $36^{\circ}$ and allow dual-Doppler winds to be synthesized. The APAR is a fuselage-radar and it uses rapid scanning of a single beam to alternate between aft and fore directions separated by $35^{\circ}$ for collecting dual-Doppler winds as it flies past a storm cluster. As described in Sect. 4, four planar array phased array radars scan the atmosphere in dual-Doppler and surveillance modes. Flight track for the APAR will be similar to that of ELDORA. 


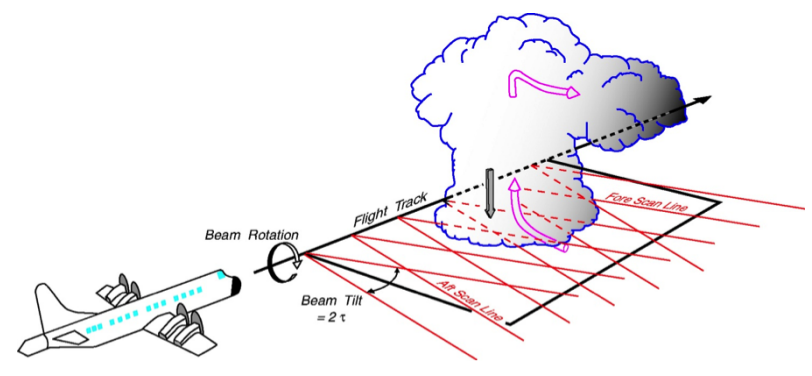

Figure 10. Radar typical flight pattern of ELDORA when collecting dual-Doppler radial winds. Dual radar beams pointing normal to the fuselage. The aft and fore radar beams are tilted by an angle $(\tau)$ of $18^{\circ}$. The antenna housed in a rotodome rotates typically 24 RPM (i.e., $144^{\circ} \mathrm{s}^{-1}$ ) about an axis parallel to the fuselage. The flight track past a hypothetical storm is shown. The radial velocities at beam intersections are used for deriving two-dimensional wind fields (Hildebrand et al., 1996).

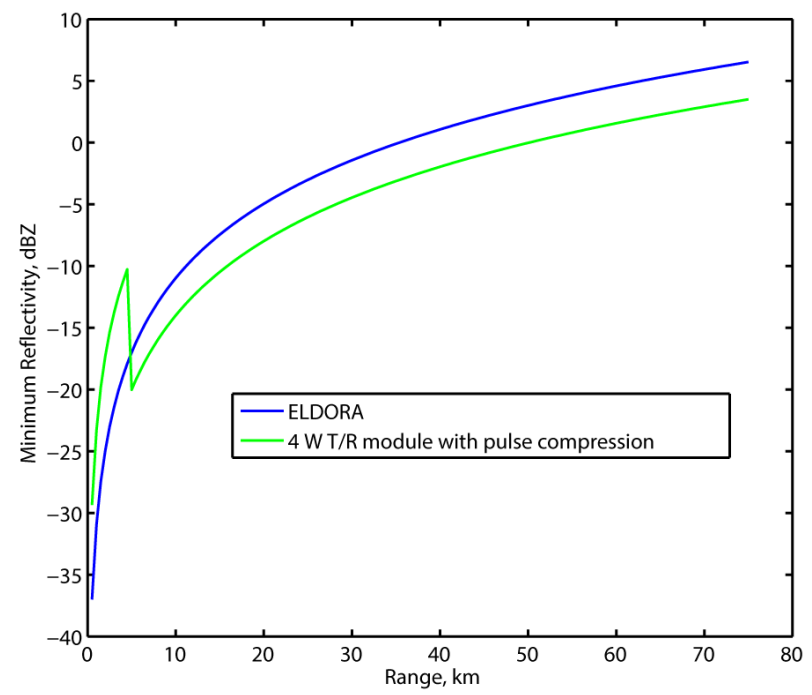

Figure 11. Sensitivities of the ELDORA and the APAR for $4 \mathrm{~W} T / \mathrm{R}$ module with pulse compression are shown as a function of range.

Technical specifications of the ELDORA radar are listed in Table 1 . The sensitivity of the ELDORA radar as a function of range is shown in Fig. 11. Typical sensitivity of the ELDORA is about $-11 \mathrm{dBZ}$ at $10 \mathrm{~km}$. The APAR uses a pulse compression scheme for attaining better sensitivity than ELDORA. The fundamental limitation of mechanically scanned radar is that it can only update measurements once per revolution. Transmitted signals in a mechanically scanned radar maintain the same polarization state and gain in all of the scan angles, but it requires a longer dwell time at each beam position for estimating reflectivity and Doppler wind measurements with a specified accuracy in the case of ELDORA. However, in an e-scan radar polarization state, antenna gain varies as the beam moves away from boresight. By limiting the scan angle away from bore sight to less than $20^{\circ}$, the above-mentioned shortcoming is minimized. The e-scan

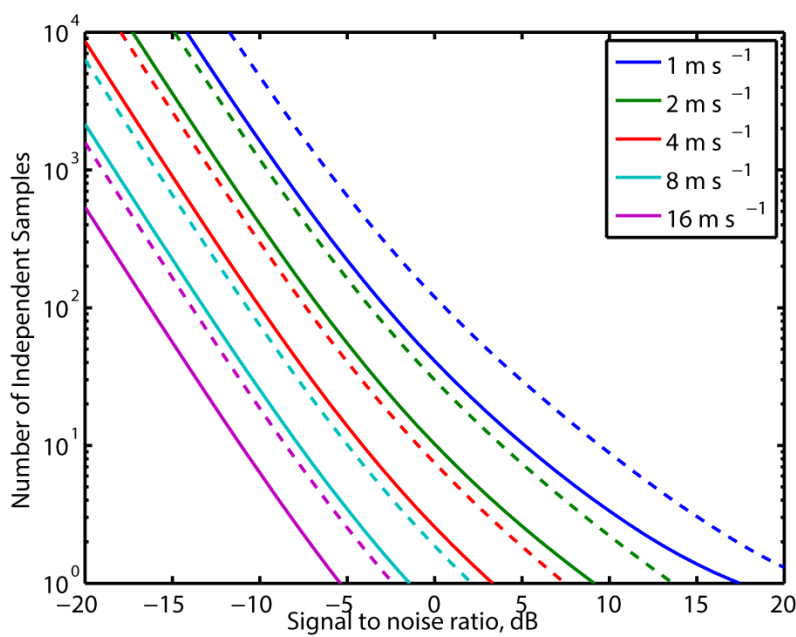

Figure 12. Requirement of number of independent samples as a function of signal-to-noise ratio for various mean velocity measurement accuracies is shown. Spectrum width is assumed $1 \mathrm{~m} \mathrm{~s}^{-1}$ and PRF is 2000 and transmit frequency is X-band. The dashed lines show corresponding values for the C-band (i.e., APAR). Higher numbers of independent samples are required at C-band than at $\mathrm{X}$-band for a specified mean velocity measurement accuracy and signal-to-noise ratio.

feature enables significantly improved temporal resolution of measurements.

ELDORA operates at X-band, whereas the APAR will operate at C-band. Signal statistics of measurements depend on transmit frequency and Doppler spectrum width. At X-band wavelength, for $1 \mathrm{~m} \mathrm{~s}^{-1}$ spectrum width, the $T_{\mathrm{D}}$ is $3.6 \mathrm{~ms}$. The number of independent samples depends on dwell time of the beam. Since the ELDORA radar scans at $144^{\circ} \mathrm{s}^{-1}$, or at $24 \mathrm{RPM}$, the beam dwells over $1^{\circ}$ sector for $7 \mathrm{~ms}$. During this dwell time, it collects only two independent samples over every $1^{\circ}$ scan angle sector. Figure 12 shows a number of independent samples required as a function of signal-to-noise ratio (SNR) for various measurements of mean radial velocity accuracies. If only two independent samples are collected, $>12 \mathrm{~dB}$ SNR is required for estimating radial mean velocity with better than $1 \mathrm{~m} \mathrm{~s}^{-1}$ accuracy. As the radar is on a moving platform, its ability to dwell for a longer period over a specified region is limited. In order to increase the number of independent samples from two to eight in a specified time interval of $7 \mathrm{~ms}$, the ELDORA used a four frequency step-chirped waveform (Girardin-Gondeau et al., 1991). It should be noted radar measurements separated in frequency by chirping are statistically independent. Eight independent samples composed of four chirped pulses and two independent samples in each frequency reduced the SNR requirement to $6 \mathrm{~dB}$ for estimating the mean radial winds within $1 \mathrm{~m} \mathrm{~s}^{-1}$ accuracy for a specified Doppler spectrum width of $1 \mathrm{~m} \mathrm{~s}^{-1}$. Doppler Nyquist interval is extended to $\pm 110 \mathrm{~m} \mathrm{~s}^{-1}$ by a staggered pulse repetition frequency technique (Doviak 
and Zrnic, 1993). The APAR will also allow to use staggered PRF for extending the Doppler Nyquist interval. The APAR uses the e-scan feature to acquire the optimal number of independent samples for achieving $1 \mathrm{~m} \mathrm{~s}^{-1}$ accuracy for a specified Doppler spectrum width of $1 \mathrm{~m} \mathrm{~s}^{-1}$ as in ELDORA. This is possible even though $T_{\mathrm{D}}$ is larger at C-band than at $\mathrm{X}$ band because it dwells at a given direction only long enough for a single pulse pair estimate. In addition to Doppler, the APAR will measure dual-polarization observations over a restricted range of scan angles from bore sight. The e-scan capability will offer flexible scan strategies for dual-Doppler, and surveillance modes of data collection.

\section{Summary and discussion}

Preliminary design specifications of the APAR that may replace the ELDORA are described in this paper. The APAR is being designed to be capable of collecting microphysical and dynamical scientific products. Design specifications of APAR are more stringent than a ground-based PAR. The airborne platform allows the measurement and collection of dual-Doppler and dual-polarization measurements to retrieve dynamical and microphysical quantities of precipitation. Multiple AESA radars on the C-130 fuselage enhance spatial and temporal resolutions of measurements.

The desired goal is to meet or exceed the current sensitivity and spatial resolution of the ELDORA radar and also to collect polarimetric measurements. It is recognized that to accomplish this with solid-state power amplifiers, the use of pulse compression is essential. The rapid scan feature and low measurement error would greatly enhance $3-\mathrm{D}$ wind estimates from an airborne phased array radar. The proposed four airborne phased array radars on NCAR's C-130 would improve spatial resolution by a factor of 2 and reduce scan volume time by a factor of 4 . In an airborne configuration, restriction of scan angles to $20^{\circ}$ will have only a limited impact on overall quality of polarization observations. APAR with dual-polarization and dual-Doppler capability (greatly improved from ELDORA) allows concurrent estimates of microphysical (e.g., precipitation types and sizes, quantitative precipitation estimation) and 3-D winds in a precipitation system.
Since overall performance of the radar system depends on an array of T/R elements and radiation patterns of patch antennas, developing a systematic and robust calibration of APAR is crucial. The goal is to estimate reflectivity within $1 \mathrm{~dB}$ and velocity within $1 \mathrm{~m} \mathrm{~s}^{-1}$. Channel equalizations of individual $\mathrm{T} / \mathrm{R}$ elements have to be performed periodically for maintaining a robust calibration standard. External calibration that relates to antenna element gain and phase, as a function of scan angle is necessary when there is a change in array configuration.

Solid state, compact T/R elements based on GaAs is the key enabling technology; only demonstrated hardware and software sub-systems will be included in the design of the AESA. EOL collaborated with MIT Lincoln Laboratories in designing C-band $\mathrm{T} / \mathrm{R}$ elements. This effort, in conjunction with the in-house development of a small, dual-polarization stack patch array will be used for developing a prototype phased array radar. The gain of the stacked patch antenna element array varies as a function of the scan angle of the beam. Also, mutual coupling between the elements affects antenna characteristics. Trade offs between scan angle and antenna performance in single and dual-polarization mode is essential for the optimal performance of the antenna. Antenna radiation characteristics as a function of scan angle, as well as performance of system in co- and cross-polarization modes will be reported in a future research article. In addition, the future article will address time required for various modes of operations, namely, dual-Doppler, surveillance, polarization, and radar signal processing schemes for long and short pulse operations, and inclusion of staggered PRF. Detailed simulation and analysis of the above-mentioned components will be used to specify an ideal operation range for the APAR. 


\section{Appendix A}

Table A1. List of acronyms.

\begin{tabular}{|c|c|}
\hline AESA & Active electronically scanned array \\
\hline APAR & Airborne phased array radar \\
\hline ASTRAIA & Analyese Steroscopic par Impulsions Aeroporte \\
\hline ATAR & Alternate transmit and alternate receive \\
\hline ATSR & Alternate transmit and simultaneous receive \\
\hline ATT & Attenuator \\
\hline C-130 & Four-engine turboprop military transport aircraft \\
\hline $\mathrm{dBZ}$ & Radar reflectivity factor \\
\hline ELDORA & Electra Doppler radar \\
\hline Electra & Turboprop airliner \\
\hline EOL & Earth Observing Laboratory \\
\hline e-scan & Electronic scanning \\
\hline FPGA & Field programmable gated array \\
\hline GaAS & Gallium arsenide \\
\hline GOES-R & Geostationay Operational Environmental Satellite - R series \\
\hline $\mathrm{H}$ & Horizontal \\
\hline HALO & High-altitude long-range research aircraft \\
\hline HIAPER & High-Performance Instrumented Airborne Platform for Environmental Research \\
\hline HPA & High power amplifier \\
\hline ICPR & Integrated cross-polar ratio \\
\hline IF & Intermediate frequency \\
\hline$K_{\mathrm{DP}}$ & Propagation phase \\
\hline LNA & Low noise amplifier \\
\hline LDR & Linear depolarization ratio \\
\hline LRU & Line replaceable unit \\
\hline MPA & Medium power amplifier \\
\hline MIT & Massachusetts Institute of Technology \\
\hline MMIC & Monolithic microwave integrated circuits \\
\hline MODIS & Moderate Resolution Imaging Spectoradiometer \\
\hline MSL & Mean sea level \\
\hline NCAR & National Center for Atmospheric Research \\
\hline NOAA & National Oceanic and Atmospheric Administration \\
\hline NSF & National Science Foundation \\
\hline NWRT & National Weather Radar Testbed \\
\hline PAR & Phased array radar \\
\hline PPI & Plan position indicator \\
\hline PRF & Pulse repetition frequency \\
\hline PS & Phase shifter \\
\hline $\mathrm{P}-3$ & Four-engine turboprop surveillance aircraft \\
\hline $\mathrm{QC}$ & Quality control \\
\hline QPE & Quantitative precipitation estimation \\
\hline QPF & Quantitative precipitation forecast \\
\hline $\mathrm{RF}$ & Radio frequency \\
\hline RHI & Range height indicator \\
\hline Rx & Receiver \\
\hline SNR & Signal-to-noise ratio \\
\hline Solo & Software for radar translation, visualization, editing and interpolation \\
\hline STSR & Simultaneously transmit and simultaneously receive \\
\hline$T_{\mathrm{D}}$ & Time-to-independence \\
\hline TDR & Tail Doppler radar \\
\hline $\mathrm{T} / \mathrm{R}$ & Transmit/receive \\
\hline $\mathrm{Tx}$ & Transmitter \\
\hline $\mathrm{V}$ & Vertical \\
\hline Vcc & Voltage source with continuous current \\
\hline$Z$ & Reflectivity \\
\hline$Z_{\mathrm{DR}}$ & Differential reflectivity \\
\hline$\lambda_{\mathrm{o}}$ & The transmit wavelength \\
\hline$\theta_{0}$ & Beamwidth along boresight of the antenna \\
\hline$\theta_{45}$ & Beamwidth when pointing $45^{\circ}$ away from boresight of the antenna \\
\hline
\end{tabular}


Acknowledgements. Authors are indebted to R. M. Wakimoto, former director of NCAR/EOL who strongly advocated key requirements of next generation airborne Doppler weather radar that are outlined in this paper. NCAR is primarily funded by the National Science Foundation. This material is based upon work supported by the National Science Foundation under cooperative grant number (M0904552). Any opinions, findings, and conclusions or recommendations expressed in this material are those of the author(s) and do not necessarily reflect the views of the National Science Foundation.

Edited by: A. Benedetto

\section{References}

Bell, M. M. and Montgomery, M. T.: Observed structure, evolution, and potential intensity of category 5 hurricane Isabel (2003) from 12 to 14 September, Mon. Weather Rev., 136, 2023-2046, 2008.

Bell, M. M., Lee, W.-C., Wolf, C. A., and Cai, H.: A Solobased automated quality control algorithm for airborne tail Doppler radar data, J. Appl. Meteorol. Clim., 52, 2509-2528, doi:10.1175/JAMC-D-12-0283.1, 2013.

Bluestein, H. B. and Wakimoto, R. M.: Mobile radar observations of severe convective storms, Meteor. Mon., 30, 105-105, 2003.

Brandes, E. A., Zhang, G., and Vivekanandan, J.: Experiments in rainfall estimation with a polarimetric radar in a subtropical environment, J. Appl. Meteorol., 41, 674-685, 2001.

Bringi, V. N. and Chandrasekar, V.: Polarimetric Doppler Weather Radar, Cambridge University Press, New York, 2001.

Chang, W., Vivekanandan, J., and Wang, T. C.: Estimation of Xband polarimetric radar attenuation and measurement uncertainty using a variational method, J. Appl. Meteorol., 53, 1099-1119, doi:10.1175/JAMC-D-13-0191.1, 2014.

Dabberdt, W. F. and Schlatter, T. W.: Research opportunities from emerging atmospheric observing and modeling capabilities, B. Am. Meteorol. Soc., 77, 305-323, 1996.

Doviak, R. J. and Zrnic, D.: Doppler Radar and Weather Observations, Academic Press, San Diego, CA, 562 pp., 1993.

Emanuel, K. A., Raymond, D., Betts, A., Bosart, L., Bretherton, C., Droegemeier, K., Farrell, B., Fritsch, J. M., Houze, R., LeMone, M., Lilly, D., Rotunno, R., Shapiro, M., Smith, R., and Thorpe, A.: Report of first prospectus development team of the US weather research program to NOAA and the NSF, B. Am. Meteorol. Soc., 76, 1194-1208, 1995.

Forsyth, D. E., Kimpel, J. F., Zrnic, D. S., Ferek, R., Heimmer, J. F., McNellis, T., Crain, J. E., Shapiro, A. M., Vogt, R. J., and Benner, W.: The National Weather Radar Testbed (Phased Array), Preprint, 32nd Conference on Radar Meteorology, Albuquerque, NM, Amer. Meteor. Soc., CD-Rom, 12R3, 2006.

Fritsch, J. M. and Carbone, R. E.: Improving quantitative precipitation forecasts in the warm season: a USWRP research and development strategy, B. Am. Meteorol. Soc., 85, 955-965, 2004.

Girardin-Gondeau, J., Baudin, F., and Testud, J.: Comparison of various coded waveforms for an airborne meteorological Doppler radar, J. Atmos. Ocean. Tech., 8, 234-246, 1991.

Houghton, J., Ding, Y., Griggs, D., Noguer, M., van der Linden, P., Xiaosu, D., Maskell, K., and Johnson, C.: Climate Change 2001: The Scientific Basis, 881, Cambridge University Press, Cambridge, UK, 2001.
Hildebrand, P. H., Lee, W.-C., Walther, C. A., Frush, C., Randall, M., Loew, E., Neitzel, R., Parsons, R., Testud, J., Baudin, F., and LeCornec, A.: The ELDORA/ASTRAIA airborne Doppler weather radar: high resolution observations from TOGA COARE, B. Am. Meteorol. Soc., 77, 213-232, 1996.

Houze, R. A. Jr., Chen, S. S., Lee, W.-C., Rogers, R., Moore, J., Stossmeister, G., Bell, M., Cetrone, J., Zhao, W., and Brodzik, S.: The hurricane rainband and intensity change experiment: observations and modeling of hurricane Katrina, Ophelia, and Rita, B. Am. Meteorol. Soc., 87, 1503-1521, 2006.

Houze, R. A. Jr., Chen, S. S., Smull, B. F., Lee, W.-C., and Bell, M. M.: Hurricane intensity and eyewall replacement, Science, 315, 1235-1239, 2007.

Hubbert, J. C., Ellis, S., Dixon, M., and Meymaris, G.: Modeling, error analysis and evaluation of dual polarization variables obtained from simultaneous horizontal and vertical polarization transmit radar. Part I: Modeling errors caused by cross-coupling, J. Atmos. Ocean. Tech., 27, 1583-1598, 2010a.

Hubbert, J. C., Ellis, S., Dixon, M., and Meymaris, G.: Modeling, error analysis, and evaluation of dual polarization variables obtained from simultaneous horizontal and vertical polarization transmit radar. Part II: Experimental data, J. Atmos. Ocean. Tech., 27, 1599-1607, 2010b.

Jorgensen, D. P., Shepherd, T. R., and Goldstein, A. S.: A dualpulse repetition frequency scheme for mitigating velocity ambiguities of the NOAA P-3 airborne Doppler radar, J. Atmos. Ocean. Tech., 17, 585-594, 2000.

Laursen, K. K., Jorgensen, D. P., Brasseur, G. P., Ustin, S. L., and Hunning, J.: HIAPER: the next generation NSF/NCAR research aircraft, B. Am. Meteorol. Soc., 87, 896-909, 2006.

Montgomery, M. T., Bell, M. M., Aberson, S. D., and Black, M. L.: Hurricane Isabel 2003: new insights into the physics of intense storms. Part I: Mean vortex structure and maximum intensity estimates, B. Am. Meteorol. Soc., 87, 1335-1347, 2006.

Montgomery, M. T. and Smith, R. K.: The genesis of Typhoon Nuri as observed during the Tropical Cyclone Structure 2008 (TCS08) field experiment - Part 2: Observations of the convective environment, Atmos. Chem. Phys., 12, 4001-4009, doi:10.5194/acp-124001-2012, 2012.

Oye, R., Mueller, C., and Smith, S.: Software for radar translation, visualization, editing and interpolation, 27th Conference On Radar Meteorology, Vail, CO, Am. Meteor. Soc., 359-361, 1995.

Ramanathan, V., Crutzen, P., Kiehl, J., and Rosenfeld, D.: Aerosols, climate and the hydrological cycle, Science, 294, 2119-2124, 2001.

Rosenfeld, D.: TRMM observed first direct evidence of smoke from forest fires inhibiting rainfall, Geophys. Res. Lett., 26, 31053108, 1999.

Schmitz, A.: An investigation to address the robustness of aircraft radar data, M. S. thesis, Meteorology, St. Louis University, USA, 188 pp., 2010

Seliga, T. A. and Bringi, V. N.: Potential use of radar differential reflectivity measurements at orthogonal polarizations for measuring precipitation, J. Appl. Meteorol., 15, 69-76, 1976.

Salazar, J. L., Knapp, E. J., and McLaughlin, D. J.: Dualpolarization performance of the phase-tilt antenna array in a casa dense network radar, IEEE International Geoscience and Remote Sensing Symposium (IGARSS) 2010, 25-30 July, 3470-3473, 2010 . 
Simpson, J., Adler, R. F., and North, G. R.: A proposed Tropical Rainfall Measuring Mission (TRMM) satellite, B. Am. Meteorol. Soc., 69, 278-295, 1988.

Smith, R. B., Carbone, R. E., and Zeng, X.: The lower atmospheric observing facilities workshop - meeting the challenges of climate system sciences, 18-19 June, Boulder, CO, USA, 44 pp., 2012.

Stephens, G. L., Vane, D. G., Boain, R. J., Mace, G. G., Sassen, K., Wang, Z., Illingworth, A. J., O’Connor, E. J., Rossow, W. B., Durden, S. L., Miller, S. D., Austin, R. T., Benedetti, A., Mitrescu, C., and the CloudSat Science Team: The CloudSat mission and the A-train: a new dimension of space-based observations of clouds and precipitation, B. Am. Meteorol. Soc., 83, 1771-1790, 2002.

Twomey, S.: The influence of pollution on the short-wave albedo of clouds, J. Atmos. Sci., 34, 1149-1152, 1977.

Vivekanandan, J., Ellis, S. M., Oye, R., Zrnic, D. S., Ryzhkov, A. V., and Straka, J.: Cloud microphysics retrieval using S-band dualpolarization radar measurements, B. Am. Meteorol. Soc., 80, 381-388, 1999a.

Vivekanandan, J., Martner, B., Politovich, M. K., and Zhang, G.: Retrieval of atmospheric liquid and ice characteristics using dualwavelength radar observations, IEEE T. Geosci. Remote, 37, 2325-2334, 1999b.

Vivekanandan, J., Zhang, G. F., and Brandes, E. A.: Polarimetric radar estimators based on a constrained gamma drop size distribution model, J. Appl. Meteorol., 43, 217-230, 2004.
Wang, H., Fang, D., and Chow, Y. L.: Grating lobe reduction in a phased array of limited scanning, IEEE T. Antenn. Propag., 56, 1581-1585, 2008

Wang, Y. and Chandrasekar, V.: Polarization isolation requirements for linear dual-polarization weather radar in simultaneous transmission mode of operation, IEEE T. Geosci. Remote, 44, 2019 2028, 2006.

Weber, M. E., Cho, J. Y. N., Herd, J. S., Flavin, J. M., Benner, W. E., and Torok, G. S.: The next-generation multimission US surveillance radar network, B. Am. Meteorol. Soc., 88, 1739-1751, 2007.

Yu, T.-Y., Orescanin, M. B., Curtis, C. D., Zrnić, D. S., and Forsyth, D. E.: Beam multiplexing using the phased-array weather radar, J. Atmos. Ocean. Tech., 24, 616-626, 2007.

Zhang, C.: Madden-Julian oscillation: bridging weather and climate, B. Am. Meteorol. Soc., 94, 1849-1870, doi:10.1175/BAMS-D-12-00026.1, 2013.

Zhang, G., Doviak, R. J., Zrnic, D. S., Crain, J. E., Staiman, D., and Al-Rashid, Y.: Phased array radar polarimetry for weather sensing: a theoretical formulation for polarization calibration, IEEE T. Geosci. Remote, 47, 3679-3689, 2009.

Zhang, L., Pu, Z., Lee, W.-C., and Zhao, Q.: The influence of airborne Doppler radar data quality on numerical simulations of a tropical cyclone, Weather Forecast., 27, 231-239, 2012.

Zrnic, D. S., Kimpel, J. F., Forsyth, D. E., Shapiro, A., Crain, G., Ferek, R., Heimmer, J., Benner, W., Mcnellis, T. J., and Vogt, R. J.: Agile-beam phased array radar for weather observations, B. Am. Meteorol. Soc., 88, 1753-1766, 2007. 